\title{
Проблема объекта в государственном региональном управлении
}

\author{
Лев Коломыц \\ Информация о статье \\ Поступила в редакиию: \\ 05.06.2019 \\ Принята \\ к опубликованию: \\ 25.10.2019 \\ УДК 332.14 \\ JEL R58
}

Дальневосточный федеральный университет, Владивосток, Россия

\section{Ключевые слова:}

регион, региональная экономика, государственное управление регионами, объект и предмет управления

\section{Keywords:}

region, regional economy, state regional administration, controlled object and subject

\begin{abstract}
Аннотация
В работе рассматриваются проблемь государственного управления сочиально-экономическими системами типа "регион», связанные с иельм рядом трудно решаемых задач. оценкой состояния управляемой системы, оценкой эффективности управляюших воздействий, определением границ управляемого объекта и пр. Высказывается гипотеза о том, что причиной появления таких проблем является неадекватность существующих управленческих подходов сложной природе объекта «регион», представляющего собой естественно-искусственную систему.
\end{abstract}

The Object Issue in the State Regional Administration

Lev Kolomyts

\section{Abstract}

The paper considers the issues of the public administration of the "region" type socio-economic systems, related to a wide range of hard to solve issues, such as assessing the state of the controlled system, assessing the efficiency of the controlling actions, identifying the boundaries of the controlled object and others. The hypothesis is proposed that the reason for such issues occurring is the inadequacy of the existing administrative approaches to the complicated nature of the "region" object, which is a natural - artificial system. According to the results of the investigation, it was found that the failures in the process of managing the regional socio-economic systems functioning and developing could be explained not only by the money scarcity allocated for these purposes, but also by the lack of the adequate knowledge concerning the controlled object in the management system. To solve this issue it is essential to set the task of creating a reliable and operational idea of the controlled object for the controlling subsystem.

\section{Введение}

Вопросы структуры и функционирования региональных социально-экономических систем, а также управления ими широко обсуждаются в

DOI: https://dx.doi.org/10.24866/2311-2271/2019-4/82-90 
научной и управленческой литературе в силу их высокой значимости для государства и общества. В данной работе делается попытка рассмотрения системы управлением региона в терминах категории объекта. Цель данного исследования состоит в рассмотрение концептуальных оснований управления региональными социально-экономическими системами.

В работе использовались исследования экономистов, эконом-географов и специалистов по государственному управлению, посвященные регионам, а также официальные документы (указы Президента Российской Федерации, распоряжения Правительства и Министерств и пр.). Использованы методы концептуального и системного анализа.

Субъект-объектная конструкция познания и деятельности известна в философии с античных времён. Согласно И. Канту, объекты познания существуют как результат активного их конструирования в творческой деятельности субъекта. Он же различал предмет и объект исследования: если первый «представлен» исследователю, то второй может быть только сконструирован в мышлении [1]. В работах Канта, Декарта, Гуссерля и других мыслителей субъектобъектные отношения выстраиваются по-разному: они могут быть независимы друг от друга, объект может быть порожден субъектом, и наоборот [2]. Познавательное и практическое отношение субъекта к объекту различны, при этом субъект-объектные отношения являются более общими, чем познание или практика, которые являются его производными. В практике они интерпретируются как отношения человека и окружающего его мира. В данной работе актуально различение гносеологических и праксиологических субъект-объектных отношений, производимое за счёт различения средств, форм и результатов познавательной и практической деятельности.

\section{Результаты и обсуждение}

Рассматривая в качестве объекта такую сложную конструкцию, как «регион», начнём с констатации наличия нескольких гносеологических (исследовательских) позиций, рассматривающих данных тип объекта. Первой является географическая, согласно которой регион рассматривается как территория, имеющая определённую совокупность наполняющих её элементов, которая определяет отличия от других территорий. Указанные элементы обладают единством, взаимосвязанностью и целостностью, которая выступает объективным условием и закономерным результатом развития данной территории [3].

Экономическая география включает в структуру системы «регион» не только географические, но и экономические элементы, рассматривая их как развивающуюся систему. По версии известного эконом-географа П.Я. Бакланова [4], её генезис выглядит так. На первой стадии основными являются географические факторы: природно-ресурсный потенциал, природные условия, географическое положение региона по отношению к рынкам. На следующем этапе происходит формирование территориальных социально-экономических комплексов и районов, включающих группы населения, инфраструктуры и хозяйственные структуры, запускаются процессы саморазвития - территориального планирования и социально-экономическое районирования. Субъект-объектные отношения трактуются в этом подходе как реализация территориальной организации хозяйства в виде субъективных процессов управления и объективных процессов самоорганизации.

Экономическое представление региона также выделяет физико- 
географическую и экономическую структуру региона, организованные вокруг его хозяйственного ядра. Региональная экономика рассматривает регион как пространственно ограниченную часть единого народнохозяйственного комплекса, т.е. как структурный элемент хозяйственного комплекса страны. Другие составляющие объекта - политико-административная, этническая, социокультурная, правовая и политическая структура [5]. Вводится таксономическая единица «экономический район», который определяется как часть территории России, включающая несколько субъектов Российской Федерации, объединенных по территориально-производственному признаку, а также вследствие относительного сходства природно-климатических и экономических условий» [6]. Важным признаком региона является наличие законченного цикла воспроизводства (непрерывного возобновления кругооборота материальновещественных, трудовых и финансовых ресурсов региона), имеющих различный уровень локализации. [7]. В зарубежных исследованиях указывается на различие регионов по структуре взаимозависимых и интегрированных друг в друга рынков товаров, труда и капитала, а также на их устройство по принципу «центр-периферия» $[8,9]$.

В советское время считалось, что районообразующие факторы и, как следствие, существование регионов имеют объективный характер, а задачей исследователя является их открытие. Основой экономического района считались территориально-производственные комплексы (далее -ТПК). На практике экономическое районирование и территориальное планирование обычно не совпадали [10].

Экономическая структура региона понималась как территориально ограниченный комплекс производств, в рамках которого развивается обмен между сосредоточенные на данной территории производствами, эксплуатирующими эффективные ресурсы, (экономическое ядро), и производствами, ориентированными на удовлетворение спроса первых (среда). Эффективное использование факторов производства требует оптимально определить границы этих комплексов и поддерживать равновесие в их границах, что должно обеспечить общее экономическое равновесие в рамках национальной экономики. [11]. Функции региона обусловлены территориальным разделением труда, комплексом производственных условий, имеющихся в регионе, и системой общественных потребностей. В регионе одновременно существуют три во многом конкурирующих группы целей экономического развития: народно-хозяйственные, региональные и отраслевые. [12].

Важно указать на натуралистический подход, которым пользуются некоторые экономисты при изучении экономических систем: считается, что в таких случаях могут применяться методы анализа, используемые по отношению к другим сложным системам (химическим, физическим, биологическим и т. д.). Например, в эволюционном подходе Й. Шумпетера сложная экономическая система ведёт себя как живой организм, которому свойственны адаптация, конкуренция, морфогенез и другие. [13].

Целями госуправления региональными системами являются а) поддержание гомеостаза либо предотвращение ухудшения состояния системы; б) вывод экономики из нежелательного состояния (спада или кризиса); и в) развитие, понимаемое как изменение качественных и количественных характеристик экономики в сторону повышения [14]. На практике государство использует по отношению к регионам один из двух подходов: выравнивание их социально- 
экономического развития или стимулирование «точек роста» [7]. Обсуждение результативности обоих подходов выходит за рамки данной статьи.

Текущие границы объектов типа «регион» достаточно произвольны, и меняются в зависимости от политических или иных предпочтений (например, недавно в состав Дальневосточного федерального округа были включены Бурятия и Забайкальский край). Границы разных составляющих объекта не совпадают друг с другом: например, в современном устройстве России сохраняется сетка административно-территориального деления РСФСР, первоначально появившаяся в 1920-е гг. для решения задач военной мобилизации. Несоответствие этой административной структуры и реального территориального распределения экономической деятельности считается экономистами одной из причин существующего дисбаланса между политическими правами, функциональными обязанностями и финансово-экономическими возможностями субъектов Федерации, что приводит к их глубокой социальной и экономической дифференциации [15].

Регион, таким образом, представляет собой сложную искусственную конструкцию, которая по-разному определяется в административном, экономическом, географическом, экономико-географическом языке. Используя лексику системного подхода, в объекте «регион» можно выделить такие элементы, как территория (ландшафт), инфраструктура (транспортная, энергетическая, промышленная, жилая, социальная), природные ресурсы (минеральные, водные, лесные, биологические), население, органы государственной власти и государственные службы. Эти разнородные элементы имеют множество связей друг с другом. С точки зрения системной теории, региону как управляемой системе, свойственны сложность, многоуровневость и иерархичность (часть управляемых подсистем имеет собственные управляемые подсистемы), отсутствие жесткой связи между управляющим воздействием и его результатами, а также ограниченность средств воздействия управляющей подсистемы на управляемую.

С праксиологической позиции регион представляет собой перечень отраслевых предметов ведения. Администрация каждого субъекта Российской Федерации, как управляющая система, включает стандартный набор элементов, организованных в Департаменты или Министерства: «Промышленность», «Экономика», «Здравоохранение», «Образование», «Социальная защита», «Природные ресурсы», и т.д. Подобная предметная «нарезка» позволяет выстроить по отношению к каждому предмету перечень контролируемых показателей, схему распределения бюджетных средств и механизмы их распределения - госпрограммы финансирования различных мероприятий. При этом различные предметные зоны часто перекрываются, но в каждой есть «слепые» зоны, находящиеся вне поля зрения и влияния управленцев.

Предметность фиксируется в периодически меняющихся перечнях критериев оценки эффективности работы органов исполнительной власти (далее ОИВ) $[16,17,18]$. В 2017 г. был принят Указ Президента России №548, содержащий 24 показателя, оценивающих эффективность работы ОИВ. Согласно этому Указу, губернаторы должны отчитываться ежегодно.

В то же время, известно не так много публикаций, рассматривающих исходные установки, лежащие в основе этих показателей. Из них следует упомянуть работы $[14,19,20,21]$, в которых авторы, в частности, подвергают сомнению точность и достоверность оценки с использованием принятых показателей 
(например, различение между конечными и непосредственными результатами деятельности ОИВ). В [22] авторы указывают, что реализуемые программы оцениваются исходя из критериев, заложенных в них самих, а сами критерии отражают не программу в целом, а эффекты отдельных мероприятий.

Тем не менее, данные критерии являются обязательными к применению всеми ОИВ и выступают основой для оценки результативности работы системы госуправления. Как утверждают упомянутые авторы, оценка посредством принятой системы показателей подвержена влиянию массы различных факторов, не учитываемых оценщиками, при этом они не фиксируют многие значимые свойства объекта и происходящие в нём процессы. Следствием применения такой системы становится существенный разрыв между выводами о состоянии управляемого объекта, которые делаются на основе данных показателей, и его реальным состоянием.

Можно сказать, что представление об объекте у органов госуправления заменено «предметами ведения» - наборами отчётных показателей и индикаторов, для изменения которых в нужном направлении осуществляются определённые действия. Вопрос о соотношении этих показателей и реальных процессов, происходящих в управляемой системе, обычно не обсуждается. Более того, сигналы «обратной связи» о реальных процессах, получаемые от системы, как правило, административно блокируются.

Другим свойством регионального госуправления является неустойчивость набора функций и полномочий различных уровней госуправления (федеральных, региональных, муниципальных) вследствие периодической передачи полномочий с одного уровня на другой, и несоответствие между закрепленными полномочиями и распределением налоговых поступлений по уровням бюджетной системы. Поскольку основой госуправления является формирование и распределение бюджетов различных уровней, современная налоговобюджетная политика не обеспечивает реальных потребностей регионов в финансовых ресурсах, не стимулирует эффективного исполнения полномочий и заинтересованности региональной и муниципальной власти в росте налогооблагаемого потенциала [23].

Тезис о нетождественности предмета и объекта государственного управления иллюстрируется следующим примером. Оценка эффективности социального блока «здравоохранение», основанная на количестве койко-мест в больницах и численности медперсонала на 10000 человек населения, базируется на представлении о наличии прямой связи между количественными показателями этих единиц и уровнем общественного здоровья. В то же время мировой опыт не подтверждает такой корреляции - например, в Европе и США количество врачей пропорционально меньше, чем в России, но эффективность системы здравоохранения существенно выше. То же самое можно сказать и об устройстве других блоков системы - «образование», «жильё», «социальное обеспечение», «финансы», «производство» и т. д.

Разрыв между гносеологическим и праксиологическим представлениями об объекте лучше всего, на наш взгляд, объясняется тезисом Г.П. Щедровицкого, который ввел в управленческий лексикон понятие «кентавр-систем» сложных системных объектов, имеющих как естественную (Е), так и социотехническую, искусственную (И) составляющие [24]. Комплексные организованности типа «регион» относятся именно к этому типу систем, поведение которых определяется большим числом слабо прогнозируемых переменных [25]. 
Как было показано выше, учёные рассматривают регион как систему и как натуральный объект, с разной степенью детализации рассматривая происходящие в нём процессы (хозяйственные, финансовые, информационные и др.). Е-часть объекта включает как натуральную часть (ландшафт, ресурсы, географию), так и искусственно созданные процессы (производственные, финансовые, социальные и прочие). И-часть объекта представляет собой предмет - знаниевое образование, определяемое только существующими видами деятельности. В отличие от кибернетической модели, в подобных системах управляющий и управляемый объект не существуют отдельно друг от друга, управляющая система и управляемый объект входят в одну надсистему [26], поэтому для осуществления управления управляющая система должна располагать знаниями об управляемой системе, средствами прогнозирования, проектирования, исследования возможных траекторий её движения.

Таким образом, особенностью управления Е/И системой является совмещение в одном представлении об объекте двух частей системы - управляемой искусственной и неуправляемой естественной, которая, в соответствии с задачами управляющей подсистемы, в ответ на управляющее воздействие должна изменяться в заданном направлении. Но поскольку в Е/И системе прямые связи между составляющими частями, как правило, отсутствуют, в ответ на управляющее воздействие происходит относительно адекватная ему реакция И-части системы, процессы же в Е-части могут меняться в нужном направлении, меняться непредсказуемо, либо не меняться вовсе. Повышение степени управляемости системы в целом возможно двумя путями: расширением И-части до границ всей системы (что невозможно), или переформатированием И-части с учётом свойств и процессов Е-части.

\section{Выводы}

Большое количество и частая смена систем индикаторов, применяемых для оценки социально-экономического состояния регионов, позволяет сделать вывод о том, что представление о структурно-функциональном устройстве объекта «регион», стоящее за набором показателей и определяющее способы измерения состояния системы и методы управления ею, не удовлетворяет требованиям управляющей системы. Причина видится в том, что верификация этого представления относительно «реального устройства объекта» либо не производится вовсе, либо производится не в должной мере, что позволяет учёным обвинять чиновников в пренебрежении результатами гносеологического подхода (более глубокими и точными знаниями об объекте) при построении и функционировании управляющей системы.

\section{Заключение}

Можно констатировать, что сбои в процессе управления функционированием и развитием региональных социально-экономических систем могут быть объяснены не только недостатком денег, выделяемых на эти цели, но и отсутствием в системе управления адекватных знаний об объекте управления, как следствие - неадекватности используемых средств управления. За краткостью текста, не обсуждены другие важные развилки - например, между управлением функционированием и развитием региона и другие. Выходом из описанной ситуации должна стать постановка перед управляющей подсистемой задачи построения достоверного и операционального представления об управляемом 
объекте.

\section{Список источников / References}

1. Волков В.А. Отношение предмета и объекта научного исследования в свете критической философии И. Канта. Управленческое консультирование, 2015, №2. сс. 146-150. [Volkov V. A. Otnoshenie predmeta i ob"ekta nauchnogo issledovaniya v svete kriticheskoi filosofii I. Kanta [The relationship between the subject and the object of scientific research in the light of the critical philosophy of I. Kant]. Upravlencheskoe konsul'tirovanie $=$ Management consulting, 2015, no. 2. pp. 146-150.]

2. Карицкий И.Н. Понятие субъекта и объекта в философии и психологии. Методология и история психологии, 2010, т. 5, вып. 1, сс. 69-101. [Karitskii I. N. Ponyatie sub"ekta i ob"ekta v filosofii i psikhologii. [The concept of subject and object in philosophy and psychology]. Metodologiya i istoriya psikhologii $=$ Methodology and History of Psychology, 2010, vol. 5, issue 1, pp. 69-101.]

3. Гладкий Ю.Н., Чистобаев А.И. Регионоведение. Москва, Гардарики, 2003. 384 с. [Gladkii Yu. N., Chistobaev A. I. Regionovedenie [Regional Studies]. Moscow, Gardariki Publ., 2003. 384 p.]

4. Бакланов П.Я. Территориальная организация хозяйства и региональное развитие. Вестник АРГО, 2012, №1. С. 32-49. [Baklanov P. Ya. Territorial'naya organizatsiya khozyaistva i regional'noe razvitie. Vestnik ARGO, 2012, №1. S. 32-49.]

5. Барбаков О.М. Регион как объект управления. Социологические исследования, 2002, № 7. C. 96-100 [Barbakov O. M. Region kak ob"ekt upravleniya. Sotsiologicheskie issledovaniya, 2002, № 7. S. 96-100.]

6. Хмелева Г.А., Семенычев В.К. Региональное управление и территориальное планирование: Учебное пособие. М.: НИЦ ИНФРА-М, 2015. 224 с. [Khmeleva G.A., Semenychev V.K. Regional'noe upravlenie i territorial'noe planirovanie: Uchebnoe posobie. M.: NITs INFRA-M, 2015. $224 \mathrm{~s}]$.

7. Новоселов А.С., отв. ред. Региональное и муниципальное управление социальноэкономическим развитием в Сибирском федеральном округе. Новосибирск: ИЭОПП CO PAH, 2014. 400 c. [Novoselov A. S., otv. red. Regional'noe i munitsipal'noe upravlenie sotsial'no-ekonomicheskim razvitiem v Sibirskom federal'nom okruge. Novosibirsk: IEOPP SO RAN, 2014. $400 \mathrm{~s}]$.

8. Friedmann J. Regional Development Policy. Boston, 1966.

9. Hoover E.M., Giarratani F. AN INTRODUCTION TO REGIONAL ECONOMICS UCEB, $1984 . \quad$ Available at: http://utenti.dea.univpm.it/sotte/Testi\%20ET_file/Hoover\%20Giarratani$\% 20$ Introduction\%20to\%20Regional\%20Economics,\%20UCEB,\%201984.pdf (accessed 04.03.2019).

10. Горшенина Е.В. Региональные экономические исследования: теория и практика. Монография. Тверь: Твер. гос. ун-т, 2009. 203 с. [Gorshenina E. V. Regional'nye ekonomicheskie issledovaniya: teoriya i praktika. Monografiya. Tver': Tver. gos. un-t, 2009. $203 \mathrm{~s}]$.

11. Минакир П.А., Демьяненко А.Н. Очерки по пространственной экономике. Хабаровск: ИЭИ ДВО РАН, 2014. 272 с. [Minakir P. А., Dem'yanenko A. N. Ocherki po prostranstvennoi ekonomike. Khabarovsk: IEI DVO RAN, 2014. 272 s].

12. Минакир П.А. Экономическое развитие региона: программный подход. М.: Наука 1983. 224 c. [Minakir P. A. Ekonomicheskoe razvitie regiona: programmnyi podkhod. M.: Nauka, 1983. $224 \mathrm{~s}]$.

13. Никоноров В.М. Методы анализа сложной экономической системы. Управление экономическими системами, 2019, №2 [Nikonorov V. M. Metody analiza slozhnoi ekonomicheskoi sistemy. Upravlenie ekonomicheskimi sistemami, №2, 2019]. Available 
at: http://uecs.ru/index.php?option=com_flexicontent\&view=items\&id=5383 (accessed 12.11.2018).

14. Баранова И.В. Совершенствование методических подходов к оценке эффективности деятельности органов власти и эффективности использования бюджетных средств. [Baranova I. V. Sovershenstvovanie metodicheskikh podkhodov k otsenke effektivnosti deyatel'nosti organov vlasti i effektivnosti ispol'zovaniya byudzhetnykh sredstv] Available at: http://safbd.ru/en/news/2012-10-20/iv-baranova-sovershenstvovanie-metodicheskihpodhodov-k-ocenke-effektivnosti (accessed 23.04.2019)

15. Ларина Н.И. Государственное регулирование регионального развития: пространственная структура власти и региональная экономическая политика. Автореф. дисс на соискание ученой степени доктора экон. наук. ИЭОПП СО РАН, Новосибирск, 2006 [Larina N. I. Gosudarstvennoe regulirovanie regional'nogo razvitiya: prostranstvennaya struktura vlasti i regional'naya ekonomicheskaya politika. Avtoref. diss na soiskanie uchenoi stepeni doktora ekon. nauk. IEOPP SO RAN, Novosibirsk, 2006].

16. Критерии комплексной оценки социально-экономического развития субъектов РФ. Постановление Правительства РФ от 11 октября 2001 г. №717 «О федеральной целевой программе «Сокращение различий в социально-экономическом развитии регионов Российской Федерации (2002-2010 годы и до 2015 года)» [Kriterii kompleksnoi otsenki sotsial'no-ekonomicheskogo razvitiya sub"ektov RF. Postanovlenie Pravitel'stva RF ot 11 oktyabrya 2001 g. №717 «O federal'noi tselevoi programme «Sokrashchenie razlichii v sotsial'no-ekonomicheskom razvitii regionov Rossiiskoi Federatsii (2002-2010 gody i do 2015 goda)»]. Available at: https://base.garant.ru/183843/ (accessed 04.02.2019)

17. «Об оценке эффективности деятельности органов исполнительной власти субъектов РФ». Указ Президента РФ №548 от 14.11.2017 [«Ob otsenke effektivnosti deyatel'nosti organov ispolnitel'noi vlasti sub"ektov RF». Ukaz Prezidenta RF №548 ot 14.11.2017]. Available at: https://www.garant.ru/products/ipo/prime/doc/71709662/ (accessed 09.03.2019).

18. «Об утверждении Перечня показателей для оценки эффективности деятельности органов исполнительной власти субъектов Российской Федерации». Указ Президента РФ №1199 от 21.08.2012. [«Ob utverzhdenii Perechnya pokazatelei dlya otsenki effektivnosti deyatel'nosti organov ispolnitel'noi vlasti sub"ektov Rossiiskoi Federatsii». Ukaz Prezidenta RF №1199 ot 21.08.2012]. Available at: http://base.garant.ru/70217848/\#ixzz5f6BpB1mj (accessed 09.03.2019).

19. Зинченко И.Ю. Оценка эффективности деятельности органов исполнительной власти субъектов РФ. Социально-экономические явления и процессы, 2014, №1 (59). С. 14-18 [Zinchenko I. Yu. Otsenka effektivnosti deyatel'nosti organov ispolnitel'noi vlasti sub"ektov RF. Sotsial'no-ekonomicheskie yavleniya i protsessy, 2014, №1 (59). S. 14-18].

20. Клименко А.В. Исполнительная власть как объект мониторинга и оценки. Проблемный анализ и государственно-управленческое проектирование, 2008, № 6. С. 55-70. [Klimenko A. V. Ispolnitel'naya vlast' kak ob"ekt monitoringa i otsenki. Problemnyi analiz i gosudarstvenno-upravlencheskoe proektirovanie, 2008, № 6. S. 55-70].

21. Меньщикова В.И. К вопросу об оценке уровня социально-экономического развития региона. Социально-экономические явления и процессы, 2011, № 9 (031). С. 123-128 [Men'shchikova V. I. K voprosu ob otsenke urovnya sotsial'no-ekonomicheskogo razvitiya regiona. Sotsial'no-ekonomicheskie yavleniya i protsessy, 2011, № 9 (031). S. 123-128].

22. Перфильев С.В., Логинов И.Н., Горбова О.Ю., Дудукина О.И. Программно-целевое управление региональным развитием. Рязань, 2012. 123 с. [Perfil'ev S. V., Loginov I. N., Gorbova O. Yu., Dudukina O. I. Programmno-tselevoe upravlenie regional'nym razvitiem. Ryazan', 2012. $123 \mathrm{~s}$ ].

23. Новосёлов А.С., Маршалова А.С., Ждан Г.В. Методологические проблемы и организационная структура управления пространственным развитием регионов. Региональная экономика и управление: электронный научный журнал, 2017, №1-1 (49). С. 
67-80. [ Novoselov A. S., Marshalova A. S., Zhdan G. V. Metodologicheskie problemy i organizatsionnaya struktura upravleniya prostranstvennym razvitiem regionov. Regional'naya ekonomika i upravlenie: elektronnyi nauchnyi zhurnal, 2017, №1-1 (49). S. 67-80].

24. Щедровицкий Г.П. Путеводитель по методологии организации, руководства и управления. [Shchedrovitskii G. P. Putevoditel' po metodologii organizatsii, rukovodstva i upravleniya]. Available at: https://gtmarket.ru/laboratory/basis/3344/3366 (accessed 22.11.2018).

25. Введение в теорию управления [Vvedenie $\mathrm{v}$ teoriyu upravleniya] Available at: https://ideafix.name/UNIVERSITY/ASU/lectures/1.pdf (accessed 15.01.2019)

26. Розин В.М., отв. ред. Философия управления: проблемы и стратегии. М.: ИФРАН, 2010. 347 c. [Rozin V. M., otv. red. Filosofiya upravleniya: problemy i strategii. M.: IFRAN, 2010. $347 \mathrm{~s}]$.

\section{Сведения об авторе / About author}

Коломыц Лев Эрландович, Школа искусств и гуманитарных наук, Дальневосточный федеральный университет. 690922 Россия, г. Владивосток, о-в Русский, кампус ДВФУ, корпус F.

E-mail: kolomytc.le@dvfu.ru

Lev E. Kolomytc, Arts and Humanities School, Far Eastern Federal University. Building F, FEFU campus, Russky Island, Vladivostok, Russia 690922.E-mail: kolomytc.le@dvfu.ru 